\title{
Dacryocele in an adult presenting as facial cellulitis
}

\author{
Prerana Kansakar ${ }^{1,2}$, MD; Gangadhara Sundar ${ }^{1}$, FRCSEd, FAMS \\ ${ }^{1}$ Department of Orbit, Ophthalmic Plastic \& Reconstructive Surgery, National University Hospital, Singapore \\ ${ }^{2}$ Department of Ophthalmology, Grande International Hospital, Kathmandu, Nepal
}

\section{Corresponding author}

Prerana Kansakar, MD

Email: prerana.kansakar82@gmail.com

Received 9 Dec 2018

Accepted 19 Dec 2018

\section{ABSTRACT}

A 47-year-old male presented with left sided facial cellulitis of one-week duration associated with a painful mass over the left medial canthal area. On examination, there was a firm, tender mass below the medial canthal tendon. Computed tomography scan revealed a bulky, cystic lesion at the left inferomedial orbit and medial maxilla with bony remodeling suggestive of a chronic dacryocele. The patient underwent marsupialization of the dacryocele at the inferior meatus with silicone tube intubation. His symptoms of epiphora resolved after surgery.

We describe a rare clinical presentation of dacryocele in an adult and its simple, yet effective treatment option.

\section{Case report}

A 47-year-old man presented with severe pain and erythema in the region of the left medial canthal area extending to the angle of the mouth for one week. On questioning, he gave a history of watering for more than 30 years.

Physical examination showed non-axial superotemporal proptosis of the left globe. Palpation revealed a diffuse, tender, firm, irreducible mass in the inferomedial aspect of the left orbit, below the medial canthal tendon. Ocular motility was mildly restricted in superior gaze. Nasal endoscopy showed round, cystic fullness in the left inferior meatus. The right nasal cavity was normal. He was started on systemic antibiotics.

Computed tomography revealed a bulky, well defined soft tissue density mass in the region of the left lacrimal sac fossa. It was extending into and expanding the left nasolacrimal duct, and its smooth anteromedial surface was bulging into the anterior left orbit displacing the left globe superotemporally. There was associated bony remodeling without

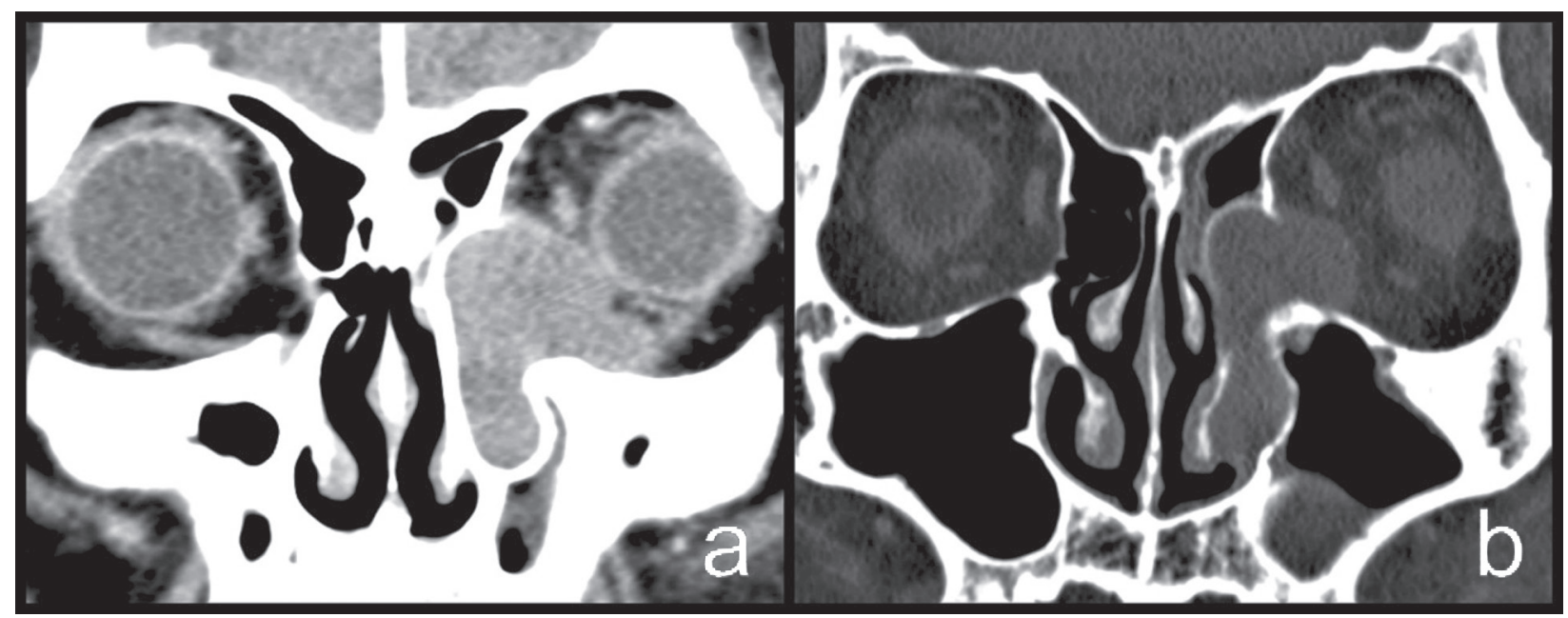

Figure 1: a - CT coronal soft tissue window; b - CT coronal bone window 
any evidence of bone destruction. The right orbit was normal with no evidence of enlargement of lacrimal drainage system (Fig. 1 a,b).

After resolution of facial cellulitis, he underwent a transnasal marsupialization of the lesion through the inferior meatus. A vertical incision was made on the inferior meatus and extended throughout the length of the nasolacrimal duct with copious drainage of yellowish, mucoid fluid (Fig. 2, a,b). The cyst wall was sent for histopathological examination. Probing and syringing was done and the lacrimal system was found to be patent. Bicanalicular intubation was then performed with silastic stents. The right nasal cavity was normal and the lacrimal system was patent on irrigation.

Microscopic examination of the fluid from the dacryocele grew Staphylococcus aureus. Histology of the cyst wall revealed acute-on-chronic inflammation and edema (Fig. 3 a,b).

The swelling resolved significantly after surgery. Nasal endoscopy at 3 months post-operatively revealed a fairly large ostium. Syringing was done and it was freely patent. Silastic tubes were removed. Patient's symptoms of epiphora had resolved completely. (Fig. 4)

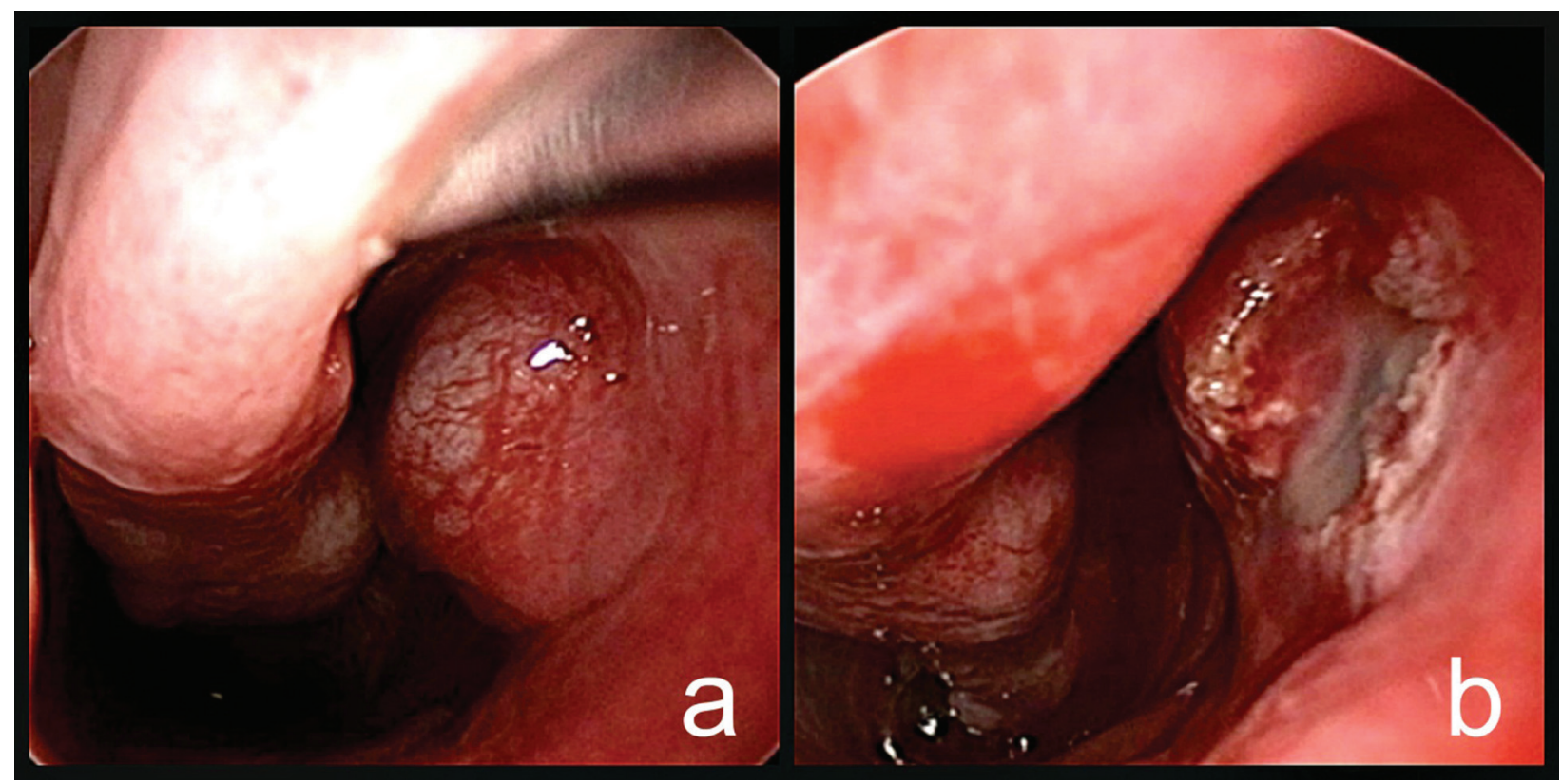

Figure 2: Endoscopic view: a - cystic swelling in the inferior meatus; $\mathbf{b}$ - vertical incision over the swelling with mucoid fluid expression

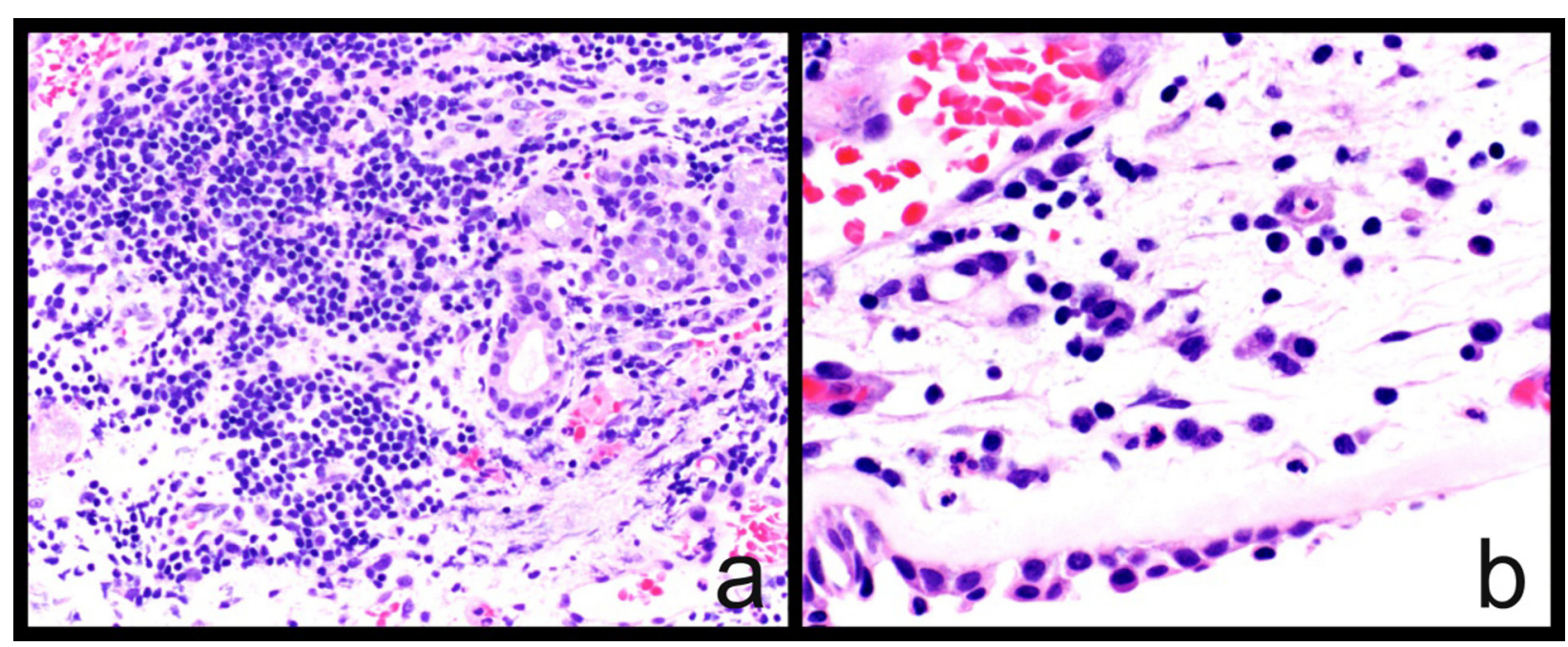

Figure 3: a, b - Clusters of mucus secreting glands with dense mononuclear inflammatory cells predominantly lymphoplasmacytes 


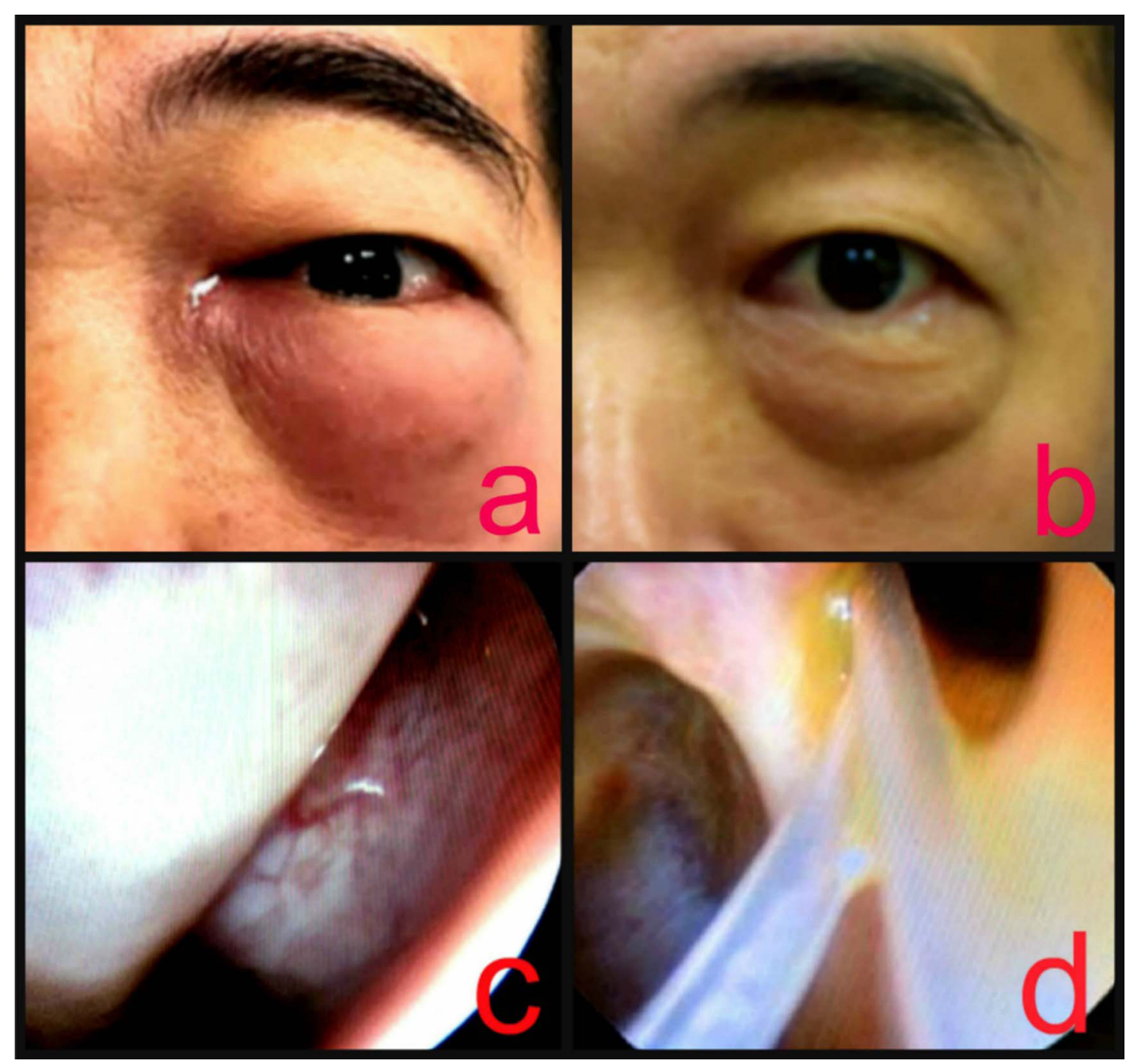

Figure 4: a, c - At presentation; b, $d$ - Three months post-op. Endoscopic view showing neo-ostium with stents in situ

\section{Discussion}

Dacryocystocele is an abnormal dilatation of the lacrimal sac frequently found in newborns as a consequence of failure of canalization of the lower end of the nasolacrimal duct. Its occurrence in adults is rare and is usually secondary to chronic inflammation, neoplasm, midface fractures, or sinonasal surgery ${ }^{1}$. Diagnosis is based on clinical examination, dacryocystography and computed tomography.

The lacrimal sac lies in the lacrimal sac fossa in the medial wall of the orbit. The valves of Rosenmuller (at the junction of common canaliculus and lacrimal sac) and Hasner (at the opening of nasolacrimal duct in inferior meatus) play an important role in maintaining the patency of this system. Proximal obstruction of the valve of Rosenmuller presents as epiphora. Distal obstruction at the valve of
Hasner will result in accompanying mucopurulent discharge with simultaneous distention of the lacrimal sac. This distal obstruction leads to further compression at the valve of Rosenmuller with the creation of a one-way conduit allowing fluid to enter the sac but preventing retrograde reflux of the sac contents ${ }^{2}$. The lacrimal sac can easily expand in the medial canthal region since there is no bony or tendinous structure to directly limit its expansion, and also because its wall is lined by respiratory epithelium.

Given the history of over 30 years of tearing, the patient probably had a congenital distal nasolacrimal duct obstruction. The chronic, progressive obstruction incited an inflammatory reaction, causing mucosal swelling and ulceration, leading to occlusive fibrosis at the junction of the common canaliculus and sac. Over time, 
progressive enlargement of the dacryocele led to bony remodeling of the entire nasolacrimal duct canal. Secondary infection of the dacryocele caused acute on chronic dacryocystitis, and delay in seeking medical help resulted in facial cellulitis.

The terms dacryocystocele and dacryocele are not interchangeable. Dacryocystocele is an abnormal cystic dilatation of the lacrimal sac whereas dacryocele involves the lacrimal sac and the entire nasolacrimal duct. Congenital dacryocystoceles make up the bulk of the disease and accounts of dacryocystoceles in adults are rare in the literature ${ }^{1-4}$. To the best of our knowledge, this is the first reported case of 'dacryocele' in an adult.

Literature reviews show various treatment options of dacryocystoceles: conservative management and drainage followed by external or endoscopic dacryoystorhinostomy, combined with or without bicanalicular intubation or dacryocystectomy ${ }^{1-5}$. Inferior meatal surgeries to overcome distal nasolacrimal duct obstructions have also been described $^{7,8}$.

In this case, we performed a transnasal endoscopic marsupialization of the dacryocele with bicanalicular stenting. We believe extending the incision along the length of the nasolacrimal duct will overcome the obstruction at various levels, if any, favoring a more successful outcome.

Studies have shown that inferior meatus endoscopy with directed treatment results in long-term improvement of epiphora in 93\% cases when performed for distal nasolacrimal duct obstructions ${ }^{8}$. The standard treatment of nasolacrimal duct obstruction is dacryocystorhinostomy (DCR) through either an external or endoscopic approach but if distal nasolacrimal duct orifice obstruction is the cause of the epiphora, less invasive procedures can be attempted. The importance of nasal endoscopy in evaluation of nasolacrimal duct obstruction needs to be highlighted as the distal nasolacrimal system and inferior meatus where the valve of Hasner opens are often left unexamined and untreated in epiphora management.

\section{Conclusion}

Dacryocystocele/dacryocele in adults should be managed surgically unlike its congenital counterpart since the obstruction is chronic and permanent. Transnasal endoscopic marsupialization with bicanalicular stenting is an alternative, minimally invasive procedure compared to the conventional dacryocystorhinostomy.

\section{References}

1. Bhaya M, Meehan R, Har-El G. Dacryocystocele in an adult: Endoscopic management. Am J Otolaryngol. 1997;18(2)131-4.

2. Lai PC, Wang JK, Liao SL. A case of dacryocystocele in an adult. Jpn J Ophthalmol. 2004;48(4):419-21.

3. Eloy $P$, Martinez A, Leruth E, Levecq L, Bertrand B. Endonasal endoscopic dacryocystorhinostomy for a primary dacryocystocele in an adult. B-ENT. 2009;5(3):179-82.

4. Woo KI, Kim YD. Four cases of dacryocystocele. Korean J Ophthalmol. 1997;11(1):65-9.

5. Yip CC, McCulley TJ, Kersten RC, Bowen AT, Alam S, Kulwin DR. Adult nasolacrimal duct mucocele. Arch Ophthalmol. 2003;121(7):1065-6.

6. Koltsidopoulos P, Papageorgiou E, Konidaris VE, Skoulakis C. Idiopathic acquired dacryocystocele treated with endonasal endoscopic dacryocystorhinostomy. BMJ Case Rep. 2013:2013.

7. Daraei P, DelGaudio JM. Inferior meatus surgery for distal nasolacrimal duct obstructions: longterm outcomes and treatment paradigm. JAMA Otolaryngol Head Neck Surg. 2014;140(8):736-41.

8. Rogers GA, Murchison AP, Wojno TH, DelGaudio JM. Inferior meatus endoscopy and directed treatment for epiphora: early experience with a novel approach. Otolaryngol Head Neck Surg. 2009;140(4):579-84. 